\title{
Crimen y economía: un acercamiento a la teoría de Gary Becker
}

\author{
Marcos David Silva Castañeda
}

\section{Resumen}

Este artículo presenta algunas aportaciones del Premio Nobel de Economía Gary Becker (1992), quien estudió los incentivos económicos que pueden provocar diversos grados de incumplimiento normativo. Según Becker (1971), quien elige conductas criminales asigna, a partir de sus costos de oportunidad, un precio diferenciado a cada delito. Este artículo presenta algunas aplicaciones de la microeconomía a un problema social sumamente relevante: la criminalidad.

Palabras clave: incentivos, racionalidad, crimen, política, justicia.

\section{Gary Becker's Microeconomic Theory of Crime}

\begin{abstract}
This article presents some contributions from the Nobel Prize winner in economics Gary Becker (1992), who studied the economic incentives that can cause varying degrees of regulatory noncompliance. According to Becker (1971), whoever chooses criminal behaviors assigns, based on their opportunity costs, a differentiated price to each crime. This article presents some applications of microeconomics to a highly relevant social problem: crime.
\end{abstract}

Keywords: incentives, rationality, crime, politics, justice. 
Twitter: @MDSC_Mexico

Es Licenciado en Ciencia Política y Administración Pública por la Facultad de Ciencias Políticas y Sociales de la Universidad Nacional Autónoma de México (UNAM) y Licenciado en Economía por la Universidad Autónoma Metropolitana, Unidad Xochimilco (UAM-X). Es además especialista en Derechos Humanos por la Universidad de Castilla La Mancha (UCLM) y en Modelos de Intervención con Jóvenes, por la Universidad Nacional Autónoma de México (UNAM-ENTS), entre otros posgrados. Actualmente, cursa su formación doctoral en un doctorado de excelencia CONACrT.

\section{Introducción}

La ciencia económica debe a Gary Becker los primeros estudios del comportamiento humano fuera de la lógica de mercado. Sus investigaciones permitieron entender conductas que fueron consideradas, durante décadas, irracionales. Sin embargo, Becker encontró explicaciones económicas a tales comportamientos a través de un principio microeconómico fundamental: un criminal busca maximizar su utilidad sujeta a diversas restricciones. Su obra puede ser resumida en los siguientes términos:

1) Expandió el análisis microeconómico a fronteras vedadas para los economistas como la criminalidad, el respeto de las leyes, etcétera.

2) Estudió comportamientos como las adicciones o los crímenes.

3) Enriqueció los estudios económicos híbridos que conjuntan diferentes ramas de conocimiento humano, por ejemplo, la economía y el derecho.

4) Entre otras cosas, su obra nos permite entender por qué un delincuente prefiere o rechaza un crimen, además nos ofrece la posibilidad de predecir conductas delictivas.

A continuación, presentaré algunas aportaciones de la teoría microeconómica de este brillante e innovador economista, para después comentar algunas aplicaciones. 


\section{Desarrollo}

Como comentábamos, Becker (1962) se interesó por aquellos comportamientos conformados por hábitos muy arraigados. Para estudiarlos partió de una hipótesis: sin excepción, el comportamiento humano está organizado por principios económicos. Por lo que la cultura o idiosincrasia no definen por qué una sociedad tiene mucha o poca criminalidad, produce abundante droga ilegal, y respeta o incumple las leyes.

Becker (1962) negó que la criminalidad pudiera ser explicada por la opresión social, en cambio, afirmaba que ésta y la pobreza son fenómenos independientes. En México, por ejemplo, estados del bajío como Guanajuato o Jalisco registran menores índices de pobreza que Oaxaca, pero tienen mayor criminalidad (CONEVAL, 2020). Etiopía no es un

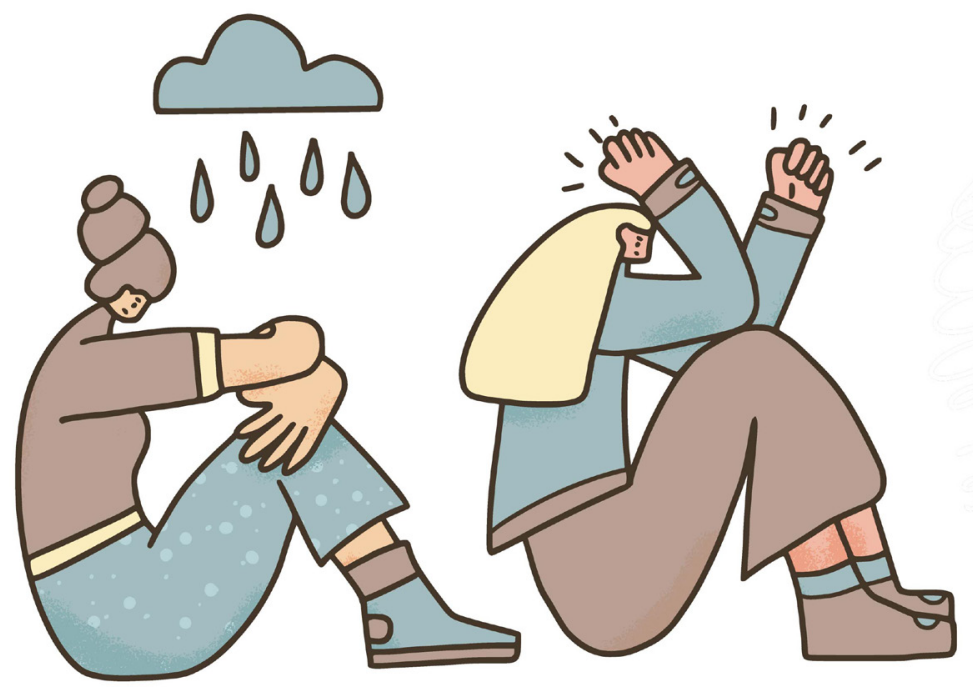
país de criminales por ser una sociedad pobre, como tampoco lo es Vietnam (CountryProfile, 2021; numbeo, 2021). California no es un paraíso, aún si es una de las economías más ricas del planeta. De hecho, es uno de los lugares más peligrosos de los Estados Unidos (CCSCE, 2021; Statista, 2020).

Según Becker (1962), lo que sí explica la criminalidad son los cálculos económicos que un delincuente realiza cuando ejecuta un crimen. Tal vez sepas que Pablo Escobar, uno de los más peligrosos narcotraficantes del siglo pasado, traficó sustancias ilícitas a Estados Unidos durante décadas, sin embargo, pocas veces nos detenemos ante un hecho un tanto intrigante: cuando Escobar traficaba droga no realizaba las mismas fechorías - más allá del tráfico de sustancias ilícitas- en EE.UU. que en Colombia. Cuando jugaba la Selección Nacional de Colombia, no así la estadounidense, gustaba de sus goles y jugadas, siendo indiferente a las victorias del equipo nacional estadounidense, sin embargo, cuánto dolor, sufrimiento y muerte provocó en la sociedad colombiana. Definitivamente, el daño que produjeron sus crímenes no tiene ninguna relación con la emoción con la que vivía los partidos de la selección colombiana ni este fervor deportivo con su comportamiento criminal.

Lo mismo podemos decir de los integrantes del Cártel de Sinaloa. Sus crímenes varían en función del país en el que se encuentren. Esto no es una paradoja, ni mucho menos una contradicción, evidentemente, tampoco una conducta atípica que debamos mandar al archivo de lo inexplicable: dependiendo del país en que se localice un criminal es el cálculo del precio que éste asigna a sus delitos. Así, Igunas aportaciones de Becker (1962) al entendimiento económico de la criminalidad son: 
1. Las conductas criminales tienen racionalidad económica. Sorprendente, ¿no?

2. Cada criminal le asigna un precio diferenciado a cada crimen. ¿Vas entendiendo cómo ve el mundo un criminal?

3. Si un delito es mayor a los costos resulta "caro"..., iy no lo comete! Un criminal, solamente elige lo que le conviene, o sea, maximiza su utilidad.

4. Si el precio es mayor a los costos, elige llevarlo a cabo.

5. Si el precio es menor al costo, no realiza la fechoría.

6. Los criminales tienen pares ordenados de crímenes, algunos se complementan, otros son sustitutos, no es que elijan un crimen y otro no. Los delincuentes cometen felonías que tienen algún tipo de conexión, es decir, enfrentan precios relativos. Esto es, un crimen y su precio determinan el precio de otro crimen, que a su vez define el de un cuarto, lo que hace suponer una especie de matriz de precios de las actividades criminales que cada delincuente va definiendo según las elecciones delictivas que va prefiriendo. Esto permite explicar por qué Escobar, o cualquier otro delincuente comete ciertos delitos en determinado momento y por qué delega o rechaza otros. ¿Interesante, cierto?

7. Las normas morales son irrelevantes en el precio que un criminal le da a un delito. Si las normas morales de una persona son elevadas no cometerá transgresión alguna incluso si tuviera la garantía de no ser visto ni detectado de ninguna forma. La religión o la fe son importantes en el comportamiento económico de las personas, porque pueden enriquecer nuestros parámetros morales. También nuestras amistades nos dan un soporte o límite moral que condiciona nuestra conducta. Sin embargo, estos mecanismos de autorregulación no influyen en la lógica económica de un criminal. Lo que quiere decir que, suponiendo una canasta de dos delitos, A y B, un delincuente no toma en cuenta la moral para calcular el precio de ambos crímenes, simplemente, opta por el más conveniente. Definitivamente, si viviera, yo no sería amigo de Escobar, ¿y tú?

8. Los cálculos que sí son significativos para un criminal son: 1) probabilidad de aprehensión, 2) precio de otros crímenes, 3) costo de oportunidad de ese crimen, 4) beneficio de realizarlo. Una baja probabilidad de aprehensión y bajo costo de oportunidad inducen a un incremento de la criminalidad.

9. Para Becker (2009), el crimen, como actividad, se parece mucho a la carpintería. En ambos casos, se requiere del cálculo anticipado de costos y beneficios. A diferencia de otras actividades económicas que no pueden prever los beneficios, en las actividades criminales éstos sí pueden ser identificados, de hecho, son un incentivo para ejecutarlos. 
10. Finalmente, la probabilidad de ser encarcelado establece, en gran parte, la elasticidad de la curva de oferta de un malhechor. Las variaciones del precio de los crímenes afectan su curva de oferta. Puede ser que un delincuente calcule ser aprehendido, pero si el sistema de justicia es poroso ponderará que, aun si es detenido, no será recluido, o será liberado en el corto plazo. Si esto ocurre de formas legales o ilegales es secundario, recordemos que esto ocurrió tanto con Escobar como con Joaquín Guzmán Loera. Ellos fueron apresados, pero también, debemos recordar, lograron escaparse del encarcelamiento. Ambos calculaban el precio de sus crímenes.

En ese mismo sentido, las aplicaciones de la teoría microeconómica de la criminalidad de Gary Becker son:

1. Una política inteligente contra el crimen consistiría en elevar el precio de cometerlo: sea en relación con otros, en la probabilidad de la aprehensión, en la imposibilidad de escapar de la prisión (legal o ilegalmente) o en la disminución del beneficio de realizarlo. ¿Razonable, cierto?

2. Si un malhechor encuentra cada vez más caro elegir un crimen, éste disminuirá su oferta. Como comentábamos, la oferta de un crimen es elástica; esto es, una variación en su precio incrementa o disminuye la oferta de ese delito en particular. A un criminal le resulta una decisión irracional, económicamente hablando, cometer una fechoría si su precio es mayor al beneficio esperado, porque perdería más de lo que ganaría. Si desea ganar X cantidad de dinero por el crimen A, pero esa cantidad no le asegurara salir de la cárcel si es aprehendido, no lo cometerá. Los maleantes buscan su beneficio y rechazan aquello que lo disminuye.

3. Si se da una conjunción favorable entre aprehensión, encarcelamiento seguro, bajo beneficio en relación con sus costes, imposibilidad de salir si se es arrestado y, en menor importancia, penas altas (sobre todo patrimoniales, más que carcelarias), los criminales enfrentarán altos precios en el mercado ilícito, por lo que preferirán no cometerlos, no porque no deseen realizarlos, sino porque les resultan perjudiciales. Esperar que un criminal tenga buena fe y que, gracias a ella, deje de ejecutar fechorías, no es realista. Es un error de apreciación que puede costar vidas humanas, altos índices de criminalidad, sufrimiento social, así como muchas familias con pérdidas irreparables.

4. Las personas de alto ingreso son más proclives a cometer crímenes, no al revés. Muchos políticos han ganado elecciones en la historia con esa falsa afirmación. ¿Interesante, no te parece? El precio de un crimen de una persona con alta capacidad económica puede evitar, por su poder económico, la posibilidad de ser detenido, encarcelado o cualquier combinación favorable. Mientras, el pobre no puede hacerlo. Lo que cambia los precios relativos de uno y otro. Quien tiene ingresos altos puede aprovechar un sistema de justicia poroso, encontrando "baratos" uno o varios delitos. 
5. Una política criminal prudente sería concentrarse en grupos sociales de alto ingreso que pudieran elegir hacer uso de su poder económico para cometer diversas fechorías.

6. Un sistema de justicia ineficiente, que no distingue el justiciable sino el poder económico del delincuente, funciona en realidad como subsidio del crimen, incrementado su oferta.

7. No se debe criminalizar al pobre. La pobreza no es una variable relevante que explique la criminalidad. Lamentablemente, en muchos países, incluido el nuestro, este error ha definido diversos programas sociales.

8. Becker no afirmó que tener ingresos altos sea sinónimo de tendencias criminales, o que toda persona que tiene riqueza sea un maleante, tan sólo señalaba que el poder económico puede provocar la reducción del costo de oportunidad de una fechoría, incrementando sus beneficios. Buscó advertirnos que la conducta criminal es más común de lo que se pudiera suponer en estratos sociales altos que en los bajos.

9. Para Becker si el encarcelamiento es excesivamente largo, puede ser más costoso para la sociedad mantener al criminal en la cárcel que reparar el daño, lo cual es completamente ineficiente (pensemos en Holanda, en ese país, las cárceles están vacías, ivaya que ahí si entienden bien a Becker!). Por lo que además del encarcelamiento, se puede preferir como castigo, en crímenes patrimoniales, una multa patrimonial tan alta que el costo de ejecutarlo sea tan elevado que resulte irracional preferirlo. Las multas sin encarcelamiento pueden funcionar mejor que el mismo encarcelamiento. No necesariamente la reclusión es la mejor forma para evitar conductas criminales, a veces, una altísima multa patrimonial puede evitarlo de una manera más efectiva.

10. En el caso de delincuentes con bajo ingreso, el enfoque tiene que cambiar, es más conveniente que puedan acceder a educación o servicios médicos, como un tratamiento odontológico o medicinas para un familiar, que al reclusorio. Permitirles optar entre educación o cárcel, entre un crédito con supervisión vinculante para operar un negocio propio o ser recluido, puede ayudarlos más de lo que podemos imaginar. Esto es, si un delincuente necesitado económicamente puede escoger entre ingresar a la economía formal, a través de un crédito con tasas de interés bajas, supervisión jurídica y comercial, así como obligaciones para cumplirlas bajo pena de ser enviado al reclusorio si no las acata, durante períodos renovables de 10 años, producirá un verdadero cambio económico en sus incentivos y costos de oportunidad. Además, si a cada pago, el crédito se va incrementado, se estimula favorablemente la supresión de conductas criminales. Un criminal no cambia porque se le acuse con su madre o 
padre, o porque le ofrezcamos perdonarlo, esa "política" lo único que provoca es el aumento de las conductas delictivas. Para desincentivar ese tipo de conductas debemos cambiar los precios relativos de la criminalidad.

\section{Conclusión}

Movilizar el conocimiento de la ciencia económica resulta perentorio. Espero que nuestro país encuentre la conveniencia de organizar su política criminal con ayuda de la microeconomía. Elegir abrazos para combatir el crimen no solamente carece de evidencia empírica, es éticamente cuestionable porque lo que está provocando es que los precios relativos del crimen disminuyan.

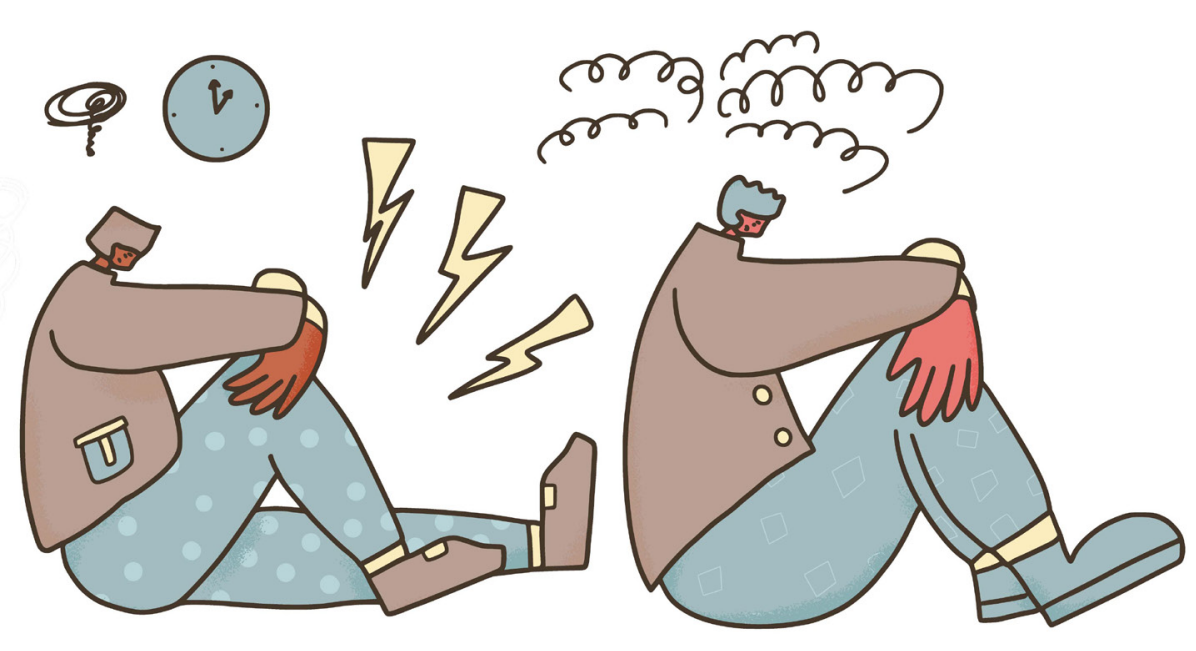

Holandatiene cárcelesvacías porque los precios, en su mercado criminal, son altos. México, por el contrario, cuenta con reclusorios saturados, así como un sistema de justicia frágil que favorece a delincuentes con mayor capacidad económica, lo que se vuelve un círculo vicioso. Nos hemos acostumbrado a rebasar el número de crímenes en una continua espiral ascendente. Actualmente, enfrentamos los índices de criminalidad más altos de los últimos 25 años en desaparición, feminicidio, asesinato doloso, tráfico de personas, etcétera. Nuestro país no enfrenta esta problemática por su idiosincrasia, genética o gastronomía, como tampoco los holandeses viven en una sociedad con criminalidad prácticamente nula porque sean holandeses. En cada uno de estos países se viven condiciones de criminalidad diferenciadas porque el costo de oportunidad de los crímenes es bajo en un caso, en el de México, y sumamente alto en otro, el de Holanda.

Espero que, en algún momento del siglo xxl, dejemos de aceptar la criminalización de la pobreza, abogando por ofertas a delincuentes de bajos recursos para que elijan entre integración a la economía formal (a través de créditos, asesorías y supervisión) o reclusión, sin olvidar imponer precios superiores a criminales con alto ingreso, disminuyendo su patrimonio, no incrementándolo, en caso de que elijan cometer una trasgresión patrimonial. Con ese propósito escribí este artículo de divulgación. 


\section{Referencias}

* Becker, G. (1962). Irrational Behavior and Economic Theory. Journal of Political Economy, 70(1), 1-13. http://www.jstor.org/stable/1827018

- Becker, G. (1965, 1 de septiembre). A Theory of the Allocation of Time. Economic Journal, 75(299), 493-517 https://doi.org/10.2307/2228949

- Becker, G. (1971). Economics of Discrimination. University of Chicago.

* Becker, G. (2009). Human Capital. University of Chicago.

* Criminalidad en Etiopía. (2021). NUMBEO. https://es.numbeo.com/criminalidad/ pa\%25C3\%25ADs/Etiop\%C3\%ADa

* CCSCE - Center For Continuing Study of the California Economy. (2021). CCSCE. https:// www.ccsce.com/Cal_Econ_Growth.php

- CountryProfile. (2021). World Development Indicators. https://databank.worldbank. org/views/reports/reportwidget.aspx?Report_Name=CountryProfile\&ld=b450fd $57 \&$ tbar $=y \& d d=y \& i n f=n \& z m=n \&$ country $=E T H$

* Informes de Pobreza y Evaluación 2020. (2020). CONEVAL. https://www.coneval.org. mx/coordinacion/entidades/Paginas/Informes_Pobreza_Evaluacion_2020.aspx

* Statista. (2020, 5 noviembre). Tasa de crímenes violentos en EE. UU., por estado 2019. https://es.statista.com/estadisticas/634038/tasa-de-crimenes-violentos-en-eeuu-por-estado/

\section{Cómo CITAR ESTE ARTículo}

* Silva Castañeda, Marcos David. (2021, septiembre-octubre). La teoría microeconómica de la criminalidad de Gary Becker. Revista Digital Universitaria (RDU), 22(5). http://doi.org/10.22201/cuaieed.16076079e.2021.22.5.7 